\title{
VALIDATION OF THE DAILY PASSIVE MICROWAVE SNOW DEPTH PRODUCTS OVER NORTHERN CHINA
}

\author{
Dejing Qiao ${ }^{1,2}$, Zhen $\mathrm{Li}^{2}$, , Wang Nianqin ${ }^{1}$, Jianmin Zhou ${ }^{2}$, Ping Zhang ${ }^{2}$, Shuo Gao ${ }^{2}$ \\ ${ }^{1}$ College of Geology and Environment, Xi'an University of Science and Technology, Shanxi, China - djqiao@ stu.xust.edu.cn, \\ younglock@163.com \\ ${ }^{2}$ Institute of Remote Sensing and Digital Earth, Chinese Academy of Science, Beijing, China - zli@ ceode.ac.cn, (zhoujm, zhangping, \\ gaoshuo)@radi.ac.cn
}

Commission III, ICWG III/IVb

KEY WORDS: Snow Depth Products, Snow Cover, Passive Microwave, Validation, Northern China

\begin{abstract}
:
Passive microwave sensors have the capability to provide information on snow depth (SD), which is critically important for hydrological modeling and water resource management. However, the different algorithms used to produce SD products lead to discrepancies in the data. To determine which products might be most suitable for Northern China, this paper assesses the accuracy of the existing snow depth products in the period of 2002-2011. By comparing three daily snow depth products, including NSIDC, WESTDC and ESA Globsnow, with snow cover product and meteorological stations data, the accuracies of the different SD products are analyzed for different snow class and forest cover fraction. The results show that comparison between snow cover derived from snow depth of NSIDC, ESA GlobSnow and WESTDC with snow cover product shows that accuracy of WESTDC and ESA GlobSnow in snow cover detecting can reach 0.70. Compared to meteorological stations data below 20cm, NSIDC consistently overestimate, WESTDC and ESA Globsnow underestimate, furthermore the product from WESTDC is superior to the others. The three products have the same tendency of significant undervaluation over $20 \mathrm{~cm}$. The WESTDC is superior to the ESA Globsnow and NSIDC in non-forest regions, whereas the ESA GlobSnow estimate is superior to the WESTDC and NSIDC in forest regions. As for the prairie and alpine snow, WESTDC has smaller bias and RMSE, meanwhile Globsnow has advantages in the snow depth retrieval in tundra and taiga snow. Therefore, we should choose the more suitable snow depth products according to different needs.
\end{abstract}

\section{INTRODUCTION}

Snow is an essential resource in the Northern China, providing water for drinking, irrigation and industry across much of the region. The snow also affects climate dynamics and the ecology (Wang et al. 2014). Therefore, our ability to acquire frequent, high quality, reliable data about the volume of water stored in the seasonal snowpack influences our ability to monitor the water resource changes. One of the key variables in forecasting the pre-melt water amount is the snow water equivalent (SWE) or snow depth (SD) (Davenport et al. 2012). The successful estimation of the SWE or SD can improve the accuracy of the snowmelt-runoff prediction and the management of the water (Kuras et al. 2008; Tanasienko et al. 2011).

Current operational water amount forecast typically rely on surface snow surveys (Li et al. 2012). However, manual snow surveys are time-consuming and expensive which make SWE or SD estimation from satellite passive microwave sensors an attractive option (Foster et al. 1991). Passive microwave remote sensing has been used to estimate snow depth and snow water equivalent because it can penetrate cloud cover and interact with the snowpack at good temporal (daily) and moderate spatial ( 25km) resolution (Derksen et al. 2010).

At present, there are three daily passive microwave (PM) snow depth or snow water equivalent products covering China: the global SWE product from the National Snow and Ice Data Center (NSIDC) (Santi et al. 2010; Tedesco et al. 2010), the Northern Hemisphere SWE product from the European Space
Agency (ESA) (Pulliainen 2006), and the snow depth product for China from the West Data Center in China (Che et al. 2008). However, there is a problem associated with both the brightness temperature difference algorithms and the assimilation algorithm is that it is difficult to determine their accuracy (Liu et al. 2014). Thus, there is a lack of reliable quantifiable indices for SWE/SD product selection in practical applications. Until now, no definitive evaluation have been performed over long time periods for northern China.

In this study, the Moderate Resolution Imaging Spectroradiometer (MODIS) snow cover (Maurer et al. 2003) and meteorological station observation data are synthesized to evaluate the accuracy of snow cover and snow depth derived from passive microwave remote sensing data. The purpose of this study is to investigate the following questions in particular:

- Accuracy of snow area extent derived from passive microwave satellite data?

- The snow depth products can be used to monitor the changes of the for snow amount over a long-term time?

- The performance of three products as a function of the various snow classes and forest cover fraction in Northern China?

\section{VALIDATION OF THE SNOW DEPTH PRODUCTS}

\subsection{Test area}

To demonstrate the performance of the passive microwave snow depth products, we choose the northern China as a test area. The 
test area is marked by grey in Chinese map at right corner of the each picture (Fig.1), which extends from $73^{\circ} \mathrm{E}$ to $135^{\circ} \mathrm{E}$ and from $35^{\circ} \mathrm{N}$ to $58^{\circ} \mathrm{N}$. The major reason of selecting the area is that the coverage area of ESA GlobSnow product is limited between latitudes $35^{\circ}$ and $85^{\circ}$ (Luojus et al. 2011). It includes two primary seasonal snow cover regions in China: Xinjiang province and northeast China. The Xinjiang region includes mountains, plains, and deserts. In the northeast China, the forest cover, which represents $40 \%$ of the total area, is the most abundant type of land cover. Farmland and grassland respectively cover $30 \%$ and $20 \%$ of the total area (Ran et al. 2012). In addition, the snow cover of test area usually appears from the end of October to the beginning of November, reaches its maximum in the end of January and the beginning of February, the rapidly decreases in March and disappears at the begging of April (Dai et al. 2012).

\subsection{Reference data}

2.2.1 Meteorological station observation data: The daily snow depth observations from 445 stations in the study area, Northern China, from 2002 to 2011 are available from the China Meteorological Administration (CMA). Snow depth is measured manually using a snow tube with a cross-sectional area of $100 \mathrm{~cm}^{2}$ at the fixed snow experiment field in stations. Before the station observation data could be used, the data with invalid values and used in the procedure of GlobSnow assimilation algorithm (marked with red point) were eliminated in the evaluation. In addition, only the pixels that featured simultaneous collection of both the ground measurements and the observations used to produce the GlobSnow, NSIDC and WESTDC products were selected. If two or more stations were located within a single pixel, their average value was taken as the value of the pixel. Finally, we selected 337 meteorological stations, and these location are illustrated in Fig.1.
2.2.2 MODIS snow cover data: In this study, we use Modis snow cover data to evaluate the accuracy of snow area extent derived from the passive microwave satellite snow depth product. The data, using the daily Climate Modeling Grid (CMG) gives a global view of snow cover at 0.05 degree resolution from the NASA Goddard Space Flight Center. Snow cover extent is mapped by processing the MOD10A1 and MYD10A1 products for a day into the CMG (Hall et al. 2002). Snow cover extent is expressed as a percentage of coverage of the input data at $500 \mathrm{~m}$ resolution in a cell of the CMG. In this study, we resampled the MODIS snow cover to 0.25 degree.

\subsection{Valuation data}

2.3.1 NSIDC AMSR-E snow depth product : The AMSR-E L3 Global SD is global daily inverted SD product based on the brightness temperatures from AMSR-E covering the period from June 2002 to October 2011 (Tekeli 2008). Pixels that are assumed to represent wet snow, mountains, rain, or other impossible pixels are excluded before SD retrieval.

The algorithm used to produce this product is derived from the method of the Chang's brightness temperature difference. However, if snow presence is detected but it is likely to be shallow, the SD is estimated to be $5.0 \mathrm{~cm}$. For medium-to-deep snow, separate retrievals for forested and un-forested fractions are combined to obtain the entire snow depth within the AMSRE pixel (Tedesco et al. 2010). The snow depth is calculated as:

$$
S D=f f * S D_{f}+(1-f f)^{*} S D_{o}
$$

where $\mathrm{SD}=$ the total sample snow depth

$\mathrm{SD}_{o}=$ the non-forested snow depth components

$\mathrm{SD}_{f}=$ forested snow depth components

$f f=$ the forest fraction
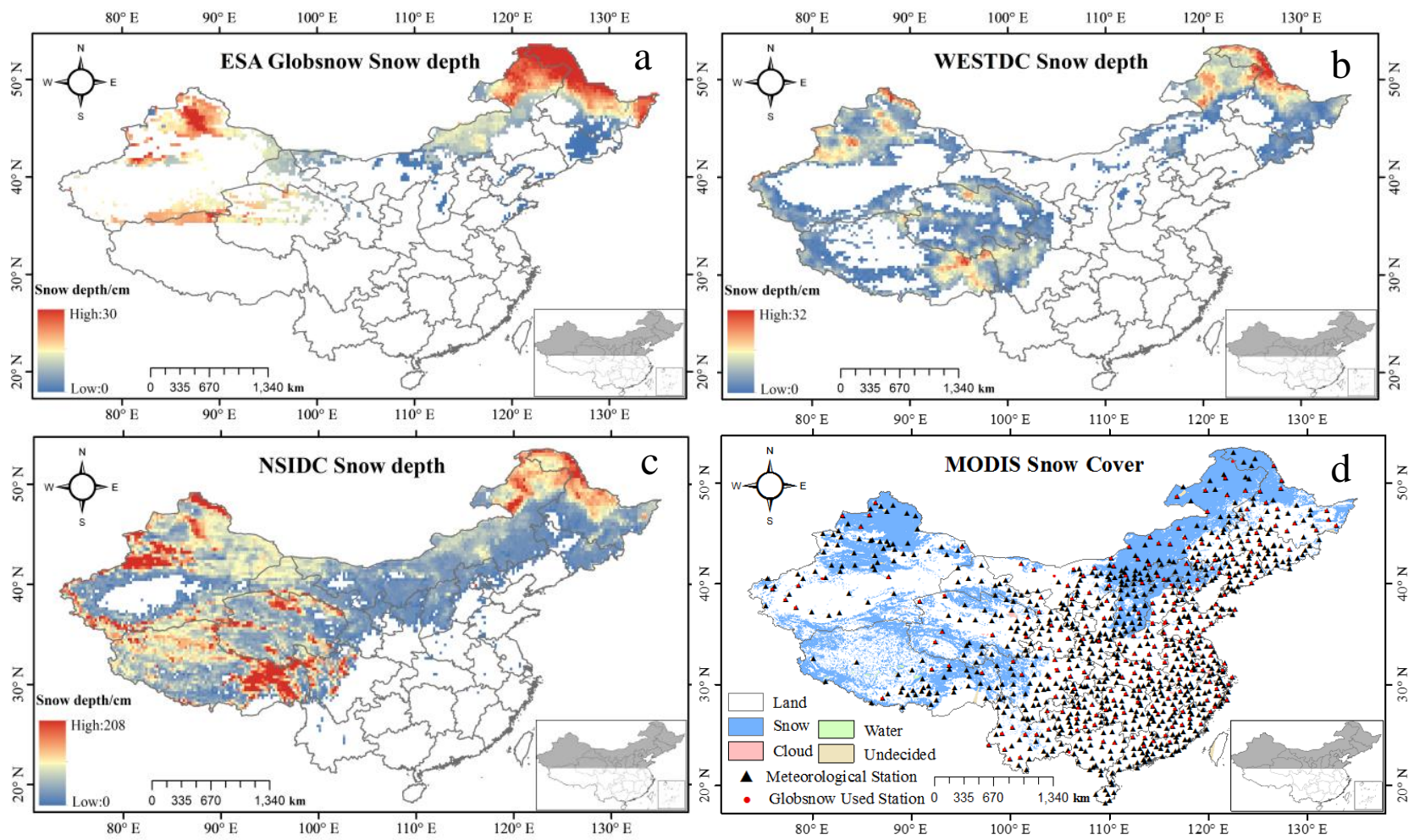

Fig.1. The Northern China daily SD data and the corresponding Modis snow cover in 1 January 2007. (a)-(c) are SD data from ESA GlobSnow, WESTDC and NSIDC. The data in (d) is the obtained from NSIDC. 
The forested snow depth $\left(\mathrm{SD}_{f}\right)$ and non-forested snow depth $\left(\mathrm{SD}_{o}\right)$ can be calculated as follows:

$$
\begin{aligned}
S D_{f}[\mathrm{~cm}] & =1 / \log _{10}\left(p o l_{36}\right) \\
& *\left(T b_{18 V}-T b_{36 V}\right) /(1-f d * 0.6) \\
S D_{o}[\mathrm{~cm}] & =\left[1 / \log _{10}\left(p o l_{36}\right) *\left(T b_{18 V}-T b_{36 V}\right)\right] \\
& +\left[1 / \log _{10}\left(p o l_{18}\right) *\left(T b_{10 V}-T b_{18 V}\right)\right]
\end{aligned}
$$

where $\quad f d=$ forest density

pol $_{18}=$ the differences between vertical and horizontal polarizations at $18.7 \mathrm{GHz}$

pol $_{36}=$ the differences between vertical and horizontal polarizations at $36.5 \mathrm{GHz}$

Finally, the estimated SD values can be obtained by snow water equivalent divided by the snow density. The snow density is obtained from a global snow density map, in which the average snow density value for each of the six seasonal classes (Sturm et al. 1995) is calculated according to in situ measurements collected in Canada and the former Soviet Union.

2.3.2 ESA Globsnow snow depth product:The Globsnow SWE product is produced by the algorithm that assimilates synoptic weather stations snow depth observations with satellite passive microwave brightness temperature (TB) data. The snow density is treated as a constant value of $0.24 \mathrm{~g} / \mathrm{cm}^{3}$. SWE is the product of snow depth and snow density. The effect of forest cover is estimated in the HUT snow emission model based on global land cover data (Takala et al. 2011).

The time series of Globsnow SWE daily product is from 1979 to present, projected onto the EASE-Grid by combining surface observations of snow depth in the PMW SWE retrieval. The single layer HUT snow emission model is used to simulate TB at each surface observation where SWE values are estimated from the observed SD, by assuming a constant snow density, assimilating with satellite TB values by optimizing the effective snow grains sizes (Larue et al. 2017).

2.3.3 Product from the WESTDC: The WESTDC snow depth product for China has been retrieved from the Scanning Multichannel Microwave Radiometer (SMMR), the Special Sensor Microwave Image (SSM/I) and the Special Sensor Microwave Image/Sounder (SSMI/S) from 1978 to the present (Che et al. 2008; Dai et al. 2015). The snow depth product is derived from the TB using the algorithm proposed by Che. This algorithm modifies the coefficient of the Change algorithm (Chang et al. 1996) using snow depth observation from meteorological stations in China and uses an average offset to remove the influence of snow density and grain size seasonal variations with a simple statistical method. The effect of forest cover is estimated by the method proposed by Foster.

$$
S D=0.72\left(T_{b, 18}-T_{b, 37}\right) /(1-0.5 f)
$$

\section{EVALUATION METHODS AND RESULTS}

\subsection{Overview of snow depth products}

For the retrieval products, the snow depth maps of the China from NSIDC (AMSR-E), ESA GlobSnow and WESTDC display significantly different spatial distributions, primarily due to their use of different algorithms. Taking the snow depth product of January1, 2007 distributions as an example, it is clear that the patterns of snow depth values including the locations of greatest snow depths contain dissimilarities in China.

In terms of snow coverage, in the same day, NSIDC products extend more regions than WESTDC product, especially the
GlobSnow products cover a smallest area. To avoid topographic influences, GlobSnow excludes mountain areas, such as the Tibetan plateau. In terms of snow depth values, NSIDC product exhibits greater snow depth values over other two products in the test area. In the same time and location, the three snow production have different pixel value.

\subsection{Comparison with MODIS snow cover}

We collected MODIS snow cover products from 4 July 2002 to 3 October 2011 to compare with the results of this study. Though MODIS snow cover products cannot provide snow depth information, we can compare the agreement or disagreement of MODIS and the passive microwave snow depth products snow extent in each of the passive microwave snow depth products pixels by resampling the MODIS snow cover products into the EASE-Grid projection. For a passive microwave snow products pixel, when the snow depth is larger than $0 \mathrm{~cm}$, we consider the pixel to be snow-covered. For the resampled MODIS pixel, the snow-cover area is a fraction of snow-covered, and when the snow-cover area is large than 50\% we consider it as a snow-cover pixel. Congalton (1991) described several methods for assessing the accuracy of remotely sensed data. First of all, we considered MODIS snowcover products as the truth because optical remote sensing has higher spatial resolution and a better comprehensive algorithm than passive microwave remote sensing. We then established the error matrices of the passive microwave snow depth products result for each day according to MODIS snow-cover

\begin{tabular}{|c|c|c|c|}
\hline \multirow{4}{*}{ MODIS } & \multirow{4}{*}{$\begin{array}{c}\text { Snow } \\
\text { Non-snow }\end{array}$} & \multicolumn{2}{|c|}{ SD products } \\
\hline & & Snow & Non-snow \\
\hline & & $\mathrm{a}$ & b \\
\hline & & $\mathrm{c}$ & $\mathrm{d}$ \\
\hline
\end{tabular}
product. Finally, we used the kappa analysis to assess the accuracy.

Table 1. Confusion matrix for remote sensing image vs. snow depth products.

Note: a,b,c and d represent the number of pixels in a particular classification category on a daily basis as shown in table1.

The kappa analysis is a stricter method to assess the coincidence in two datasets. The kappa statistic was defined as (Congalton 1991):

$$
\text { kappa }=\frac{P_{o}-P_{e}}{1-P_{e}}
$$

Where

$$
\begin{aligned}
& P_{o}=\frac{a+d}{n} \\
& P_{e}=\frac{(a+b)(a+c)+(c+d)(b+d)}{n^{2}}
\end{aligned}
$$

Table 2. The Confusion matrix for remote sensing image vs. snow depth products.

\begin{tabular}{cccc}
\hline & NSIDC (AMSR-E) & ESA GlobSnow & WESTDC \\
\hline Kappa & 0.6099 & 0.7861 & 0.7334 \\
\hline
\end{tabular}

In general, in order to determine the precision of detecting snow of the snow products, the kappa coefficient is calculated. Compared with the snow cover area of the MODIS products, ESA GlobSnow and WESTDC snow depth products have a relatively good consistency, while the accuracy of NSIDC data is poor. Therefore, we should choose the reasonable microwave remote sensing data when using microwave data to remove cloud from MODIS. 


\subsection{Comparison with meteorological station observation}

An overall assessment of the algorithm performance was further achieved by comparing snow depth retrievals with the reference to meteorological station observation data. Figure 2 contains a histogram that shows the trend between snow products with Fig. 3 shows the significantly seasonal change trend. The date of annual maximum SD is in February or March. The WESTDC and ESA GlobSnow SD data maintain better consistency with meteorological station observations. The annual maximum SD of NSIDC (AMSR-E) is obvious overestimation. However, compared with the stations, the snow start time of WESTDC and ESA GlobSnow SD data is a slight delay.

Then, we compared and analysed the time series analysis of all weather stations with snow depth products in northern China. The statistical results are shown in the table 3 .

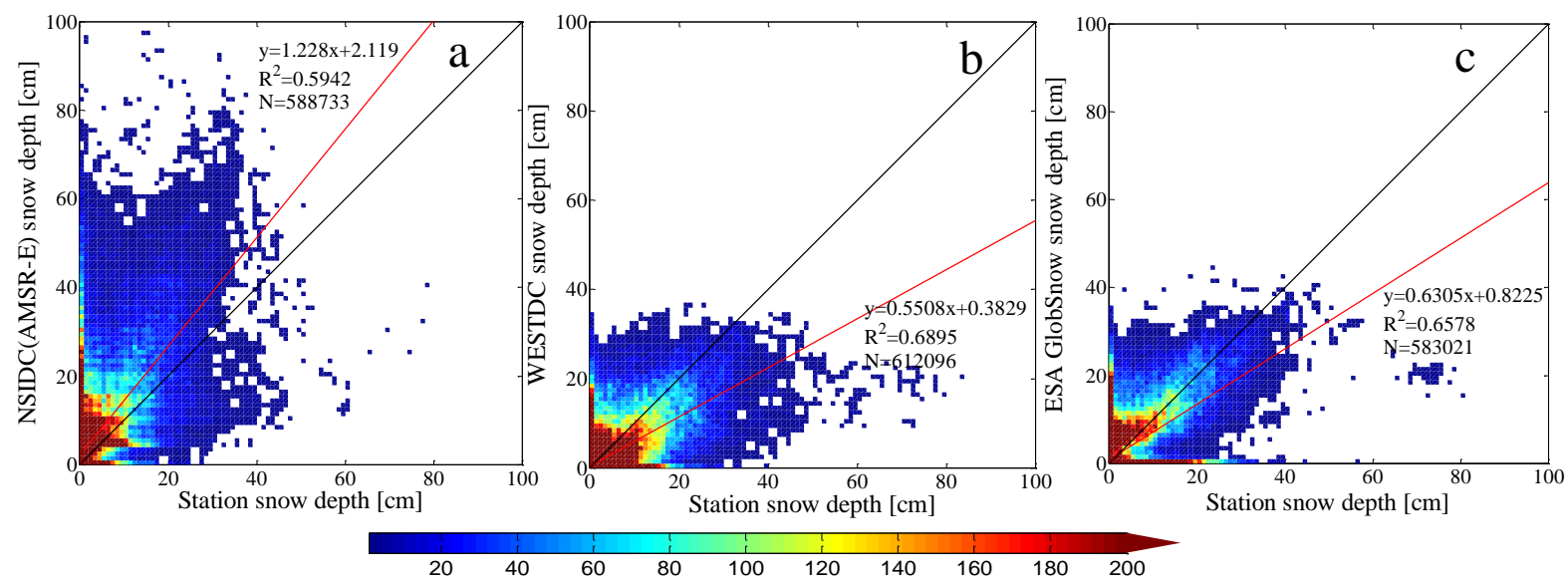

Fig.2. Evaluation of passive microwave in northern china, SD products are compared to meteorological station observation data for each snow depth products: (a) NSIDC (AMSR-E); (b) WESTDC; (c) ESA GlobSnow. The color scale represents the data count of scattered points, computed by using square (side length of $5 \mathrm{~cm}$ ) centered at each data point.

station data from each October to the follow May during the period of validity of the products.

Fig.2 (a) shows that the snow depth of the NSIDC is higher than meteorological station observation data in general. Fig.2 (b) and (c) presents that the ESA GlobSnow and WESTDC product are underestimated. However, the ESA Globsnow is closer to the meteorological station observation.

3.3.1 Time-series analysis: The meteorological stations usually can represent these local weather change trend. In order to test whether the product and the meteorological station data have good consistency in time series, a long-term sequence comparison was made for each product. Over the same period in the northern China. Next, we select two meteorological stations data for analysis.

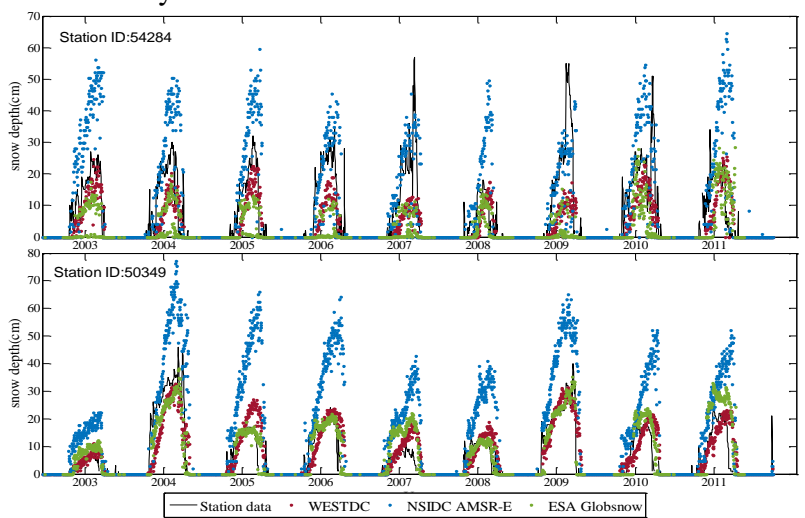

Figure 3. The snow depth are compared to in situ observation from 2002 to 2011
Table 3. The Confusion matrix for remote sensing image vs. snow depth products.

\begin{tabular}{cccc}
\hline & corr & RMSE & Bias \\
\cline { 2 - 4 } WESTDC & 0.35 & 1.47 & -0.02 \\
AMSR-E & 0.30 & 4.26 & 1.66 \\
Globsnow & 0.33 & 2.07 & -0.02 \\
\hline
\end{tabular}

Table 3 shows that the statistical results for long-term time series of SD products change tendency. It is obvious that WESTDC product has highest correlations coefficient and lowest bias and RMSE, which indicates that WESTDC product is more consistent with the meteorological stations.

3.3.2 Different snow depth analysis: The accuracies of three daily snow depth products were also assessed by comparing the results with meteorological station observations to illustrate the correlation and magnitude of the differences between the meteorological stations and the derived SD products. To display the trend more clearly for different snow depth, accumulations are displayed in $2 \mathrm{~cm}$ steps in fig.4. It is obvious that the estimated snow depth does not increase monotonically with increasing snow depth.

In fig.4, the snow depth of the ESA GlobSnow and WESTDC products are underestimated. The NSIDC product is overestimated when the snow depth is less than $40 \mathrm{~cm}$, and the snow depth is obviously underestimated when it exceeds $40 \mathrm{~cm}$. The three types of snow depth products have been underestimated as the snow depth increases when the snow is more than $40 \mathrm{~cm}$. However, the underestimation existences is ineviatable in all the snow depth prodcuts due to the highfrequency microwave "saturation" in deep snow. 


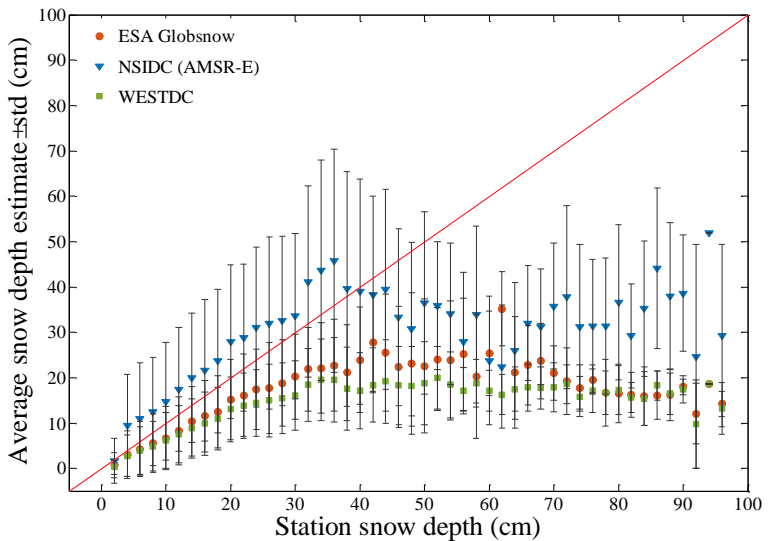

Figure 4 . The snow depth are compared to in situ observation from 2002 to 2011

Theoretically speaking, because the microwave upwelling radiation emitted from the ground by scattering no longer decreases with increasing snow depth at higher microwaves frequencies $(37 \mathrm{GHz})$, passive microwave SD retrieval algorithms do not have the ability to detect deep snow and thus have a tendency to systematically underestimate the SD in such conditions (Takala et al. 2009).

The products of the ESA GlobSnow and WESTDC presents obvious underestimation. However, the snow depth by the NSIDC products show an overestimate for the values less than $40 \mathrm{~cm}$. The three products have a better linear relationship with the station snow depth for the value below $30 \mathrm{~cm}$. Compared with the NSIDC products, a better linear relationship exists between station snow depth with GlobSnow and WESTDC products for values below $20 \mathrm{~cm}$, and WESTDC provides a clear improvement in retrieval accuracy (lower REMS, and bias).

\subsection{Analysis of the accuracy with different snow class and forest fraction}

Owing to the influences of the snow properties on the snow retrievals and the various environments, the accuracy of SD products present different results for different snow classes and forest fraction.

In forested areas, uncertainties are mostly due to snowvegetation interactions that strongly affect snow cover variability (especially with different types of forests) and the vegetation contribution (emission and transmission), which are difficult to model precisely in an inversion scheme (Roy et al 2012; Vander et al. 2015). As for forest cover fraction, In this study, five types of forest cover including evergreen needle leaf, evergreen broadleaf, deciduous needle leaf, deciduous broadleaf, and mixed forest, were derived from the land cover map. Due to the lack of stem volume or biomass of forest, we used the forest cover data as indirect vegetation information. The forest cover fraction data within each pixel of the passive microwave remote sensing data were obtained according to these forest cover data. Although evergreen coniferous forest covers a small proportion of the study area, all of the primary forests are deciduous (Ran et al. 2012).

The snow class Sturm categorizes the snowpack in the Northern Hemisphere into six classes: tundra, taiga, maritime, prairie, alpine, and ephemeral. The classification is defined by a unique ensemble of comprehensive characteristics, including snow density, depth, crystal morphology, and grain size features within each snow layer, all of which directly affect the SD retrievals. In our study area, there are four classes listed above in table.4.
To link all of the accuracy results with these classes of each meteorological station, table4 describes the detail of the comparisons between the station SD and the satellite-derived SD products for each snow class for the period between 2002 and 2011.

The bias and RMSR values of the WESTDC and GlobSnow products are smaller than that of the NSIDC (AMSR-E) product because these two methods using the observed snow depth at stations. Furthermore, because more observed snow depths were used to develop the WESTDC product algorithm than the GlobSnow product, the results from the WESTDC product are closer to the observations. Therefore, the GlobSnow product algorithm could be greatly improved if more Chinese stations snow data were input.

Table 4. Root mean square error (RMSE) and bias for the relations between meteorological stations and SD products for different snow classes and forest fraction

\begin{tabular}{ccccccc}
\hline & \multicolumn{3}{c}{ Bais $(\mathrm{cm})$} & \multicolumn{3}{c}{ RMSE $(\mathrm{cm})$} \\
\cline { 2 - 7 } & NSIDC & ESA & WestDC & NSIDC & ESA & WestDC \\
\hline$f f>20 \%$ & 1.45 & 0.15 & 0.06 & 6.24 & 2.88 & 2.09 \\
$f f<20 \%$ & 1.93 & 0.02 & 0.05 & 7.12 & 2.62 & 3.19 \\
tundra & 0.93 & -0.45 & -1.71 & 8.61 & 6.24 & 7.23 \\
taiga & 4.63 & 0.14 & -0.56 & 11.91 & 5.29 & 4.98 \\
prairie & 2.15 & 0.31 & -0.07 & 6.58 & 4.34 & 2.87 \\
alpine & 2.14 & -0.49 & -0.20 & 7.97 & 5.58 & 3.74 \\
\hline
\end{tabular}

In this comparison, the SD values obtained from the CMA meteorological stations were again regarded as the reference, and the bias and RMSE values between the observed and retrieved SD values are listed in Table 4. The comparison indicates that the NSIDC (AMSR-E) product overestimates SD for both forest and non-forest regions. This overestimation may arise from the use of incorrect snow properties, including higher snow density and smaller snow grain size value, in this global algorithm (Kelly et al. 2003). In forest regions, the SD from WESTDC presents better consistency with the station values, whereas the NSIDC product presents overestimation, because the algorithm of the WESTDC product considers the forest influences. In non-forest regions, the bias and RMSE from the GlobSnow are smaller than the others because the algorithm utilizes the observed snow depths at meteorological stations.

In the terms of the snow class, the NSIDC (AMSR-E) presents obvious systematic overestimates in all snow classes. ESA Globsnow product presents the better accuracy for the tundra and taiga snow classes, and the overall bias is lower compared to the WESTDC product. However, the bias and RMSE of the WESTDC snow depth product are lower in comparison to the other two classes.

\section{SUMMARY AND CONCLUSIONS}

In this study, the northern China daily passive microwave snow depth from the ESA Globsnow, NSIDC and WESTDC were validated though comparisons with MODIS snow cover data and snow depth from the China Meteorological Administration over the time period 2002 to 2011 to demonstrate the accuracies of the typical stand-alone brightness temperature difference algorithms and assimilation approach used in snow depth retrieval.

According to snow depth measurements at the meteorological stations in Northern China, the NSIDC snow depth is significantly higher than the other snow depth data and meteorological stations observation. Snow depth from WESTDC is closer to the meteorological stations observation than the snow products from ESA GlobSnow and NSIDC. 
Because that the algorithm of snow depth from WESTDC is developed by modifying the coefficient and removing the seasonal bias by empirical offset. The snow depth product from ESA GlobSnow, which assimilates the meteorological stations snow depth data, is much more accurate than the NSIDC.

Further comparison analysis for the accuracy with different snow classes and forest fraction presents that snow depth from WESTDC is better agree with the meteorological stations observation data than NSIDC and ESA GlobSnow for the prairie and alpine snow class. Nevertheless, the snow depth from ESA GlobSnow has better correspondence for the tundra and taiga snow class. In term of forest cover fraction, in forest regions, the snow depth from WESTDC presents better consistency in forest regions. However, the snow depth from ESA GlobSnow has advantage in non-forest regions over the other products.

In addition, comparison between snow cover derived from snow depth of NSIDC, ESA GlobSnow and WESTDC with MODIS snow cover shows that accuracy of WESTDC and ESA GlobSnow in snow cover detecting can reach 0.70 . Therefore, we should choose the reasonable microwave remote sensing data when using microwave data to remove cloud from MODIS. In conclusion, the snow depth from WESTDC appears to be the superior product in vast majority of cases, with the exception of its tendency to slightly underestimate. Although our method of processing the reference meteorological stations snow depth data and MODIS snow cover data may introduce a bias into our assessment of snow depth products, these unavoidable errors are systematic and have a similar impact on all three products.

\section{ACKNOWLEDGEMENTS}

The authors would like to thank to all the data providers: the European Space Agency (ESA), the National Snow and Ice Data Center (NSIDC), and the Environmental and Ecological Science Data Center for West China (WESTDC). This study was supported by the National Key Research and Development Program of China (No.2016YFA0600304), Science \& Technology Basic Resources Investigation Program of China "Investigation on snow characteristics and their distribution in China" (No.2017FY100502) and the Natural Science Foundation of China (No. 41471065, 41471066 \& 41572287). We thank all anonymous reviewers for their helpful comments and suggestions, which significantly improved this paper.

\section{REFERENCES}

Chang, A.T.C., Foster, J.L., and Hall, D.K., 2015. Effects of forest on the snow parameters derived from microwave measurements during the boreas winter field campaign. Hydrological Processes, 10(12), pp. 1565-1574.

Che, T., Li, X., Jin, R., Armstrong, R., and Zhang, T.J., 2008. Snow depth derived from passive microwave remote-sensing data in china. Annals of Glaciology, 49(1), pp. 145-154.

Congalton, R.G., 1991. A Review of Assessing the Accuracy of Classifications of Remotely Sensed Data. Remote Sensing of Environment, Vol. XXXVII, pp. 35-46.

Dai, L.Y., Che, T., and Ding, Y.J., 2015. Inter-Calibrating SMMR, SSM/I and SSMI/S Data to Improve the Consistency of Snow-Depth Products in China. Remote Sensing, 17, pp. 72127230.

Dai, L.Y., Che, T., Wang, J., and Zhang, P., 2012. Snow depth and snow water equivalent estimation from AMSR-E data based on a priori snow characteristics in Xinjiang, China. Remote Sensing of Environment, 127(14-29), pp. 14-29.
Davenport, I.J., Sandells, M.J., and Gurney, R.J., 2012. The effects of variation in snow properties on passive microwave snow mass estimation. Remote Sensing of Environment, 118(4), pp. 168-175.

Derksen, C., Toose, P., Rees, A., Wang, L., English, M., Walker, A., and Sturm, M., 2010. Development of a tundra-specific snow water equivalent retrieval algorithm for satellite passive microwave data. Remote Sensing of Environment, 114(8), pp. 1699-1709.

Foster, J.L., Chang, A.T.C., Hall, D.K., and Rango, A., 1991. Derivation of snow water equivalent in boreal forests using microwave radiometry. Arctic, 44(5), pp. 147-152.

Jagt, B.J.V., Durand, M.T., Margulis, S.A., Kim, E.J., and Molotch, N.P., 2015. On the characterization of vegetation transmissivity using lai for application in passive microwave remote sensing of snowpack. Remote Sensing of Environment, 156, pp. 310-321.

Hall, D.K., Riggs, G.A., Salomonson, V.V., DiGirolamo, N.E., and Bayr, K.J., 2002. MODIS snow-cover products. Remote Sensing of Environment, 83(1), pp. 181-194.

Kelly, R.E., Chang, A.T., Tsang, L., and Foster, J.L., 2003. A prototype amsr-e global snow area and snow depth algorithm. IEEE Transaction on Geoscience and Remote Sensing, 41(2), pp. 230-242.

Li, Z., Xing, Q., Liu, S.Y., Zhou, J.M., and Huang, L., 2012. Monitoring thickness and volume changes of the Dongkemadi Ice Field on the Qinghai-Tibetan Plateau (1969-2000) using Shuttle Radar Topography Mission and map data. International Journal of Digital Earth, 5(6), pp. 516-532.

Larue, F., Royer, A., De Sève, D., Langlois, A., Roy, A., and Brucker, L., 2017. Validation of globsnow-2 snow water equivalent over eastern canada. Remote Sensing of Environment, 194, pp. 264-277.

Liu, J.L., Li, Z., Huang, L., and Tian, B.S., 2014. Hemisphericscale comparison of monthly passive microwave snow water equivalent products. Journal of Applied Remote Sensing, 8(1), pp. 084688 .

Luojus, K., Pulliainen, J., Takala, M., Lemmetyinen, J., Derksen, C., Metsamaki, S., and Bojkov, B., 2011. Investigating Hemispherical Trends in Snow Accumulation Using Globsnow Snow Water Equivalent Data. In: Ieee International Geoscience and Remote Sensing Symposium (Igarss), pp. 3772-3774.

Maurer, E.P., Rhoads, J.D., Dubayah, R.O., and Lettenmaier, D.P., 2003. Evaluation of the snow-covered area data product from MODIS. Hydrological Processes, 17(1), pp. 59-71.

Pulliainen, J., 2006. Mapping of snow water equivalent and snow depth in boreal and sub-arctic zones by assimilating space-borne microwave radiometer data and ground-based observations. Remote Sensing of Environment, 101(2), pp. 257269.

Ran, Y.H., Li, X., Lu, L., and Li, Z.Y., 2012. Large-scale land cover mapping with the integration of multi-source information based on the Dempster-Shafer theory. International Journal of Geographical Information Science, 26(1), pp. 169-191.

Roy, V.A.L., Wong, E.L.M, Ko, B.C.B., Chao, C.T., Yan, S.C., Yan, B.P., Wu, J.C., and Che, C.M., 2008. Ambipolar charge transport in dna molecules. Advanced Materials, 20(7), pp. 1258-1262.

Santi, E., Pettinato, S., Brogioni, M., Macelloni, G., Montomoli, F., Paloscia, S., and Pampaloni, P., 2010. A Pre-Operational Algorithm for the Retrieval of Snow Depth and Soil Moisture from Amsr-E Data. Ieee International Geoscience and Remote Sensing Symposium, pp. 3777-3780.

Sturm, M., Holmgren, J., and Liston, G.E., 1995. A seasonal snow cover classification system for local to global applications. Journal of Climate, 8(5), pp. 1261-1283. 
Takala, M., Luojus, K., Pulliainen, J., Derksen, C., Lemmetyinen, J., Karna, J.P., Koskinen, J., and Bojkov, B., 2011. Estimating northern hemisphere snow water equivalent for climate research through assimilation of space-borne radiometer data and ground-based measurements. Remote Sensing of Environment, 115(20), pp. 3517-3529.

Takala, M., Pulliainen, J., Metsamaki, S.J., and Koskinen, J.T., 2009. Detection of Snowmelt Using Spaceborne Microwave Radiometer Data in Eurasia From 1979 to 2007. Ieee Transactions on Geoscience and Remote Sensing, 47(9), pp. 2996-3007.

Tanasienko, A.A., Yakutina, O.P., and Chumbaev, A.S., 2011. Effect of snow amount on runoff, soil loss and suspended sediment during periods of snowmelt in southern West Siberia. Catena, 87(1), pp. 45-51.

Tedesco, M., and Narvekar, P.S., 2010. Assessment of the NASA AMSR-E SWE Product. Ieee Journal of Selected Topics in Applied Earth Observations and Remote Sensing, 3(1), pp. 141-159.

Tekeli, A.E., 2008. Early findings in comparison of AMSRE/Aqua L3 global snow water equivalent EASE-grids data with in situ observations for Eastern Turkey. Hydrological Processes, 22(5), pp. 2737-2747.

Wang, J., Li, H.X., Hao, X.H., Huang, X.D., Hou, J.L., Che, T., Dai, L.Y., Liang, T.G., Huang, C.L., Li, H.Y., Tang, Z.G., and Wang, Z.Y., 2014. Remote sensing for snow hydrology in China: challenges and perspectives. Journal of Applied Remote Sensing, 8(25), pp.084687. 